\title{
LA JUSTICIA CIVIL ORDINARIA EN LOS TRIBUNALES DEL ÁREA DE ORTIGUEIRA DURANTE EL SIGLO XVII ${ }^{1}$
}

\section{CIVIL ORDINARY JUSTICE IN THE COURTS OF THE AREA OF ORTIGUEIRA IN XVII ${ }^{\text {TH }}$ CENTURY}

\author{
Mónica F. ARMesto \\ Departamento de Dereito Público Especial \\ Facultade de Dereito \\ Universidade de Santiago de Compostela (USC) \\ 15782 Santiago de Compostela, A Coruña \\ monica.fernandez@usc.es
}

Recibido: $17 / 07 / 2017$

Aceptado: 02/03/2018

RESUMEN: El señorío jurisdiccional en Galicia, cuya investigación se había paralizado en la última década, a menudo fue tachado de inactivo por la Historiografía, especialmente, tras la implantación de la Real Audiencia. A partir de la identificación de las jurisdicciones que en el siglo XIX darían lugar a la comarca coruñesa de Ortigueira, en el presente artículo se estudia la operatividad de sus juzgados, estableciéndose las relaciones entre estos y la segunda instancia real. Además de analizarse la naturaleza de las causas a ellos elevadas y, por último, las funciones y perfiles de oficiales de justicia y litigantes.

PALABRAS CLAVE: señorío jurisdiccional, justicia ordinaria, área de Ortigueira, causas civiles, jueces de señorío, litigantes, hombres buenos.

ABSTRACT: The jurisdictional domain in Galicia, whose investigation had been stopped in the last decade, was often branded as inactive by Historiography, especially, after the settlement of the Real Audiencia. Through the identification of the jurisdictions which in XIX ${ }^{\text {eth }}$ century shaped the area of Ortigueira, in this article we study the running of their courts and the relations between them and the second royal instance. Besides, it isanalysed the nature of causes and, finally, the functions and profiles of court clerks and litigants.

KEYWORDS: jurisdictional domain, ordinary courts, area of Ortigueira, civil causes, lordly judges, litigants, meter-auditors.

\footnotetext{
El presente trabajo se ha elaborado en el marco del Proyecto "Culturas urbanas: las ciudades interiores en el NO ibérico, dinámicas e impacto en el espacio rural” (HAR2015-64014-C3-3-R), financiado por el Ministerio de Economía y Competitividad (MINECO) y el Fondo Europeo de Desarrollo Regional de la Comisión Europea (FEDER), así como del Proyecto "Rebellion and Resistance in theIberianEmpires, $16^{\text {th }}-19^{\text {th }}$ centuries" (RESISTANCE-H2020-MSCA-RISE-2017) financiado por el Programa de Investigación e Innovación Horizonte 2020 de la Unión Europea a través de la acción Marie Sklodowska-Curie (acuerdo de subvención No 778076).
} 


\section{LA JUSTICIA ORDINARIA: PUNTO DE PARTIDA HISTORIOGRÁFICO}

La subordinación de los tribunales de señorío a las reales audiencias a comienzos de la Edad Moderna constituyó el cambio fundamental operado en materia de justicia, consecuencia de la recepción tardía del derecho romano. En Galicia, esto se produjo tras la implantación de la Real Cédula de 8 de agosto de 1480, por la cual Isabel I instauraba el corregimiento -o gobernación- formado por el gobernador Acuña y el Licenciado Chinchilla, precedente inmediato de la Real Audiencia. Su principal misión era la de pacificar el Reino, así como proteger a los vasallos frente de los abusos de los poderosos, cuyas tropelías inmediatas se materializaban en la administración de justicia. A tal fin, gobernador y letrado serían envestidos de jurisdicción civil y criminal en primera instancia y apelación, exclusiva en los casos de corte y apelación directa de sus sentencias definitivas a la Reina, contando -según el tenor de la provisióncon el carácter común de ser "nuestros juices en todo el dicho Reino de Galicia". Aunque no se podrá hablar de Audiencia Real hasta 1514, la llegada de Acuña y Chinchilla vaticinaba un cambio importante en el organigrama judicial tardomedieval, pues avistaba la instauración de un órgano de justicia intermedio entre los tribunales de señorío y la Chancillería de Valladolid (1371). En este estado de cosas, cabe interrogarse sobre el nuevo significado que, iniciado el período moderno, adquiere el entramado jurisdiccional y de superposición de señoríos sobre la población a nivel administrativo.

Los estudios sobre la Real Audiencia cuentan con una tradición que se remonta a la década de los 80 del siglo pasado, en consonancia con un panorama historiográfico internacional prolífico en análisis de fondos judiciales. Notoriamente en Galicia, destacó la tesis pionera de Laura Fernández Vega en que, aun partiendo de una hipótesis política, se analizan los trazos institucionales de la Real Audiencia y sus relaciones con otros tribunales del reino. Véase justicias ordinarias e Intendencia ${ }^{3}$. Se ocupa también de la Real Audiencia Antonio Eiras Roel al profundizar, años después, en el problema de su consideración como órgano de gobierno, su administración por personal foráneo y la asunción práctica del poder por una oligarquía de funcionarios ${ }^{4}$. Al albor de esta nueva línea de investigación, se habría de ir realizando toda una serie de trabajos a lo

2 ORTEGO GIL, P. (2011). "La fuente limpia de justicia: la Real Audiencia de Galicia”. En Czeguhn, I. (dir.). Die Höchstgerichtsbarkeitim Zeiltalter Karls V. Einevergleichende Betrachtung. Baden Baden: Nomos, p. 134.

3 FERNÁNDEZ VEGA, L. (1982). La Real Audiencia de Galicia, órgano de gobierno en el Antiguo Régimen: 14801808, 3 Vol., A Coruña: Deputación.

4 EIRAS ROEL, A. (1984): "Sobre el origen de la Audiencia de Galicia y sobre su función de gobierno en la época de la Monarquía Absoluta”. Anuario de Historia del Derecho Español, LIV, Madrid, 1984, pp. 323-384. 
largo de los años 80 y 90 sobre instituciones hasta la fecha no estudiadas en Galicia. Al igual que Laura Fernández Vega, las investigaciones de María López Díaz en cuanto a sociología del poder municipal de Santiago y Lugo a mediados del siglo XVIII ${ }^{5}$, Juan Granados Loureda sobre la Intendencia ${ }^{6}$, o el de María Luísa González Ríos y Manuel Artaza Montero sobre las Juntas del Reino en los siglos XVI a XVIII, arrojarían luz sobre otras instituciones de la Galicia moderna hasta entonces no trabajadas ${ }^{7}$. Si bien, solo los trabajos de Xoán Miguel González Fernández en la década de los 90 sobre el Asistente de la Quintana y la justicia ordinaria de Bouzas y Vigo centrarían su interés en la actividad judicial del señorío ${ }^{8}$, más allá de los aspectos gubernativo-administrativos, que marcaron una tendencia historiográfica definida, fundamentalmente, en tres líneas:

- La línea de la Historia rural, proveniente de una serie de monografías sobre Xallas, Ulla y Salnés, perfeccionada por Pegerto Saavedra con su memoria de doctorado sobre la economía y sociedad de la provincia de Mondoñedo en el Antiguo Régimen, en la cual se reserva un capítulo a las cargas señoriales, la organización jurisdiccional y los conflictos sociales?. Complementándose dicha investigación, años más tarde, con un trabajo de Antonio PresedoGarazo sobre administración nobiliaria y pleitos en el señorío de Montaos durante el siglo XVI ${ }^{10}$. En cuanto, entrada la década de 2000, Anastasio Santos Iglesias Blanco, a semejanza de Pegerto Saavedra, reservaba un capítulo de su tesis a la relación entre los oficiales de justicia -sobre todo, jueces y escribanos- de los estados de Amarante, juicios de residencia y pleitos elevados ante los jueces ordinarios ${ }^{11}$.

5 LÓPEZ DÍAZ, M. (1991): Oficios municipales de Santiago a mediados del siglo XVIII. A Coruña: Estudios Mindonienses; LÓPEZ DÍAZ, M. (1992): "El Concejo de Lugo en los siglos XVI-XVII, su estructura orgánica y composición social". En $1^{\circ}$ Simposio de Historia da Administración Pública. Santiago de Compostela: EGAP, pp. 363-377; M. LÓPEZ DÍAZ (1993/94): “Origen y configuración de una magistratura del señorío del arzobispo compostelano: el juez seglar de la Quintana (1545-1599)”. Cuadernos de Estudios Gallegos, 41 (106), pp. 153-165.

6 GRANADOS LOUREDA, E., (1976): Un ejemplo de comisariado político en la España del siglo XVIII: la Intendencia de Galicia. Tesis de licenciatura: Universidade de Santiago de Compostela.

7 ARTAZA MONTERO, M. y GONZÁLEZ RÍOS, M. L. (1993): Las juntas del Reino de Galicia en el siglo XVII. A Coruña: Fundación Pero Barrié de la Maza.

8 GONZÁLEZ FERNÁNDEZ, X. M. (1995): La justicia local y territorial en la Galicia de Antiguo Régimen, Vol. I y II. Tesis inédita: Universidade de Santiago de Compostela.

9 SAAVEDRA FERnÁndeZ, P. (1985): Economía, Política y Sociedad en Galicia: la provincia de Mondoñedo 1480-1830. Madrid: Xunta de Galicia.

${ }^{10}$ PRESEDO GARAZO, A. (2004): "Un ejemplo de administración señorial secular en la Galicia del siglo XVI: el estado de Montaos". Anuario de Historia del Derecho Español, 74, pp. 701-757.

11 SANTOS IGLESIAS, A. S. (2008). La Casa de Amarante. Siglos XVI-XIX, Santiago de Compostela: Universidad [recurso electrónico]. 〈http://www.usc.es/hmoderna/web/uploads/publicacions/arquivo/860/54099abf98-1_pst. pdf) [Consultado: 02/12/2016]. 
- Los estudios en torno a los poderes municipales, cuya representante principal es María López Díaz ${ }^{12}$. Quien, en la década de los 90, emprendería la investigación en instituciones municipales como colofón de su tesis doctoral, al tiempo que publicaba otros trabajos de relevancia relacionados con la jurisdicción concejil a lo largo de los siglos modernos ${ }^{13}$. No obstante, deja sin tocar la praxis judicial, verdadera configuradora de normas en el Antiguo Régimen.

- La línea sobre litigiosidad propiamente dicha, minoritaria y poco frecuente en Galicia hasta la década de los 90. En cierto modo, inaugurada por el capítulo de tesis de Isidro Dubert, base para un artículo posterior sobre el funcionamiento de la jurisdicción ordinaria -real y señorial- relativo a las causas de índole familiar, con la firme particularidad frente a la línea de trabajo imperante de centrarse en la litigiosidad civil ${ }^{14}$. Si bien el mejor exponente es la propia investigación doctoral de Xoán Miguel González Fernández sobre la litigiosidad en primera instancia en los juzgados de Bouzas, Vigo y Asistente de Santiago entre el último tercio del siglo XVII y el siglo XVIII ${ }^{15}$. A la cual se le sumaría en la década siguiente la investigación de Raquel Iglesias Estepa sobre infrajudicialidad, en su memoria de licenciatura ${ }^{16}$, y posteriormente sobre criminalidad y sus formas de represión en el ámbito territorial del Arzobispado de Santiago durante el siglo XVIII, ya en su tesis de doctorado ${ }^{17}$.

Trabajos notables todos ellos, pese a haber fijado su interés en lo institucional -cayendo en ocasiones demasiado en el formalismo-, en el señorío como distribuidor de pechos y cargas -fuente económica, por lo tanto- y la prevalencia de la Real

${ }^{12}$ LÓPEZ DÍAZ, M. (1984): La justicia señorial en la Galicia del siglo XVIII. Tesis de Licenciatura: Universidade de Santiago de Compostela.

13 Vid., nota 5.

${ }^{14}$ DUBERT GARCÍA, I. (1990). "La conflictividad familiar en el ámbito de los tribunales señoriales y reales en la Galicia del Antiguo Régimen (1600-1830)". Obradoiro de Historia Moderna: homenaje al Profesor Antonio EirasRoel, pp. 73-102; I. DUBERT GARCÍA (1990): Historia de la familia en Galicia durante la época moderna. 1550-1830. (Estructura, modelos hereditarios y conflictividad). A Coruña: Ediciós do Castro.

15 Vid., nota 8.

${ }^{16}$ IGLESIAS ESTEPA, R. (2000). La conflictividad "sorda”: un estudio sobre la criminalidad a fines del Antiguo Régimen. Tesis de Licenciatura: Universidade de Santiago de Compostela; R. IGLESIAS ESTEPA (2001). "La conflictividad 'sorda', un estudio sobre la criminalidad a finales del Antiguo Régimen. Obradoiro de Historia Moderna, 10, pp. 247-273.

${ }^{17}$ IGLESIAS ESTEPA, R. (2004). Las Quiebras del orden cotidiano: comportamientos criminales en la sociedad gallega a fines del Antiguo Régimen. Tesis de Doctorado: Universidade de Santiago de Compostela; resumida en el libro divulgativo IGLESIAS ESTEPA, R. (2007). Crimen, criminales y reos: la delincuencia y su represión en la antigua provincia de Santiago entre 1700 y 1834 . Vigo: Nigratea. 
Audiencia. Pues, cuando se han centrado en el señorío, han tendido a ver su justicia como reducto de la época medieval -mediatizada por la anterior- $y$, más que fijarse en su funcionamiento, lógica y eficacia, han atendido al estudio de disensiones entre la comunidad. He aquí la razón de que los trabajos sobre litigiosidad civil resulten muy minoritarios en el panorama historiográfico gallego e internacional frente a la abundancia de trabajos sobre justicia criminal, fruto de una tradición que se remonta a los primeros estudios de PièrreChaunu sobre la documentación judicial de las bailías normandas en los años $60^{18}$. Además de tratarse de un elenco de trabajos relativamente antiguos, ya que la investigación en justicia ordinaria constituye una línea paralizada durante los últimos 10 años. Sin todavía haberse superado ese análisis parcial de la misma, basado en la prevalencia de la Real Audiencia como órgano de justicia, desatendiendo la función de los juzgados señoriales en el Ordenamiento Jurídico de Antiguo Régimen y que, cuando se centran en su actividad, incluso en el caso de Xoán Miguel González Fernández, atienden a aspectos fundamentalmente sociales. Del mismo modo que la escasez de fuentes anteriores al siglo XVIII en Galicia, unida a la mayor dificultad que éstas entrañan, ha motivado un cuadro parco en investigaciones relativas a los siglos XVI y XVII, lo que hace que, transcurrida más de una década desde la lectura de la tesis de Raquel Iglesias aún haya que reivindicar la necesidad de hacer investigación en justicia civil ordinaria anterior al siglo XVIII ${ }^{19}$.

\section{OBJETIVOS Y METODOLOGÍA}

El empleo de la documentación generada por juzgados señoriales atiende al objetivo fundamental de analizar su funcionamiento como órganos de justicia en sí mismos, no subordinados a la Real Audiencia de Galicia. Se trata de aprehender la lógica de pervivencia de unos tribunales heredados de la Edad Media en el marco del Ordenamiento Jurídico Moderno. Se pretende, además, poner punto y final a la preferencia historiográfica por los -sin duda, más llamativos- casos penales y otorgar el lugar que le corresponde a lo civil en el rango de las preocupaciones de la comunidad en el día a día. Esto es, el reflejo de la litigiosidad a través de los recursos existentes: disposición de la tierra, derechos sobre ésta, sistema de herencia o situaciones debitorias desprendidas de una mala coyuntura agrícola o económica general.A

\footnotetext{
${ }^{18}$ Prólogo de Pegerto Saavedra a la obra de Xoán Miguel González Fernández (1997). La conflictividad judicial ordinaria en la Galicia Atlántica (1670-1820). Bouzas y otros juzgados gallegos del siglo XVIII, Vigo: Instituto de Estudios Vigueses, p. 9.

${ }_{19}$ IGLESIAS ESTEPA, R. (2004). Las Quiebras del orden cotidiano... op., cit., sin paginar.
} 
este fin, se procede al análisis de la actividad de los tribunales de lo que en la Edad Moderna constituyeron los señoríos de las tierras de Ortigueira. Hoy llamadas comarca de Ortegal. El área geográfica más septentrional de la Península Ibérica, comprendida por las antiguas jurisdicciones de Cedeira, Ortigueira, As Pontes de García Rodríguez, Grañas do Sor, Mañón, Mogor y Bares, además de los cotos de Roupar y Cabalar -ínsitos respectivamente en As Pontes y Cerdido-. A tales efectos, fue concebido un análisis cuantitativo basado en la media duración (siglo XVII). Luego, se procedió al vaciado de la documentación, fijándose especialmente en cortes coincidentes con las décadas de 1639-1649, 1659-1669 y 1679-1689 a los efectos de cubrir en profundidad el siglo y observar posibles dinámicas de evolución de la litigiosidad a lo largo de los años. La muestra extraída de 417 expedientes de los 1.234 respectivos al total de causas correspondiente al siglo XVII constituye un conjunto representativo a la hora de arrojar conclusiones fidedignas a nivel histórico.

Previamente al recuento de las causas elevadas ante cada uno de estos juzgados, hubo de proceder a la identificación de los espacios de poder dentro del área ortigueiresa -señoríos- con el apoyo de las fuentes fiscales. Las tierras de Ortigueira en el Antiguo Régimen no conformaban unidad administrativa común, ya que pertenecían a señores jurisdiccionales diferentes, y todavía hasta el advenimiento del gobierno gaditano de 1812 no sería instituida su entidad comarcal. Así pues, resulta fundamental a la hora de abordar investigaciones sobre justicia moderna -y no siempre se ha hecho-, delimitar el marco de los señoríos para saber quién ejercía la jurisdicción -a nivel geográficosobre qué tierras y -a nivel humano- sobre quién. A partir de la identificación de los jueces en los distintos juzgados ordinarios se ha podido validar la operatividad de estos en sus respectivos señoríos jurisdiccionales cotejando el Interrogatorio del Marqués de Ensenada (1752), a la par de la consulta de la cartografía jurisdiccional del geógrafo gallego Xavier Río Barja ${ }^{20}$. Conviene advertir aquí alguna variación de titularidad jurisdiccional en el paso del siglo XVII al XVIII, como el ocurrido en el caso del señorío deCerdido que, de la Casa de Lemos, pasaría al Marqués de San Sadurnino. Igualmente, salvando las distancias con el siglo XVII, debido a la escasez de censos de población y fiabilidad de estos, se elabora un cómputo de vecinos según el Censo de Floridablanca (1787) en vistas a obtener, al menos aproximativamente, la mayor o menor fortaleza de los señores de estas tierras ${ }^{21}$.

${ }^{20}$ RÍO BARJA, X. (1990). Cartografia xurisdiccional de Galicia no século XVIII. Santiago de Compostela: Consello da Cultura Galega.

${ }^{21}$ Censo de 1787 "Floridablanca” (1987), V. IV. Madrid: Numen Numerus. 


\section{LOS SEÑORÍOS}

\subsection{El señoreo sobre las tierras de Ortigueira en el siglo XVII}

Se conoce como "tierras de Ortigueira" el conjunto de jurisdicciones medievales que en los albores de la época contemporánea pasaron a constituir la comarca del mismo nombre, lo que en términos geográficos se conoce como tierras de Ortegal, tierras del Sor y tierras de Eume central, con diferencias muy apreciables ente sí. Por Decreto de 9 de octubre de 1812 se ordenó la estructura del partido judicial que hoy en día engloba los cinco términos municipales originarios de la comarca: el de Ortigueira al Norte, Cedeira al Oeste, Cerdido al Sudoeste, Manhón al Este y, finalmente, As Pontes de García Rodríguez al Sur. Geográficamente, se ubica en la extremidad norte de la actual provincia de A Coruña, aunque en Antiguo Régimen este conjunto de jurisdicciones se hallaba entre las provincias colindantes de Mondoñedo y Betanzos ${ }^{22}$. Perteneciéndole a la última las jurisdicciones deCedeira, Cerdido, Moeche, As Pontes y Ortigueira, en cuanto caían en la primera: Bares, Mogor, Grañas do Sor, Landrove y Mañón. Esto, que a ojos contemporáneos puede parecer una atrocidad administrativa, antes de Floridablanca no suponía dificultad ninguna. Galicia constituía una complicada trama territorial y de dominios sin continuidad geográfica, ni mucho menos políticoterritorial, debido a la propia conformación de los señoríos, condicionados por una dinámica de herencias, compras y donaciones. De forma que, las mal llamadas "siete provincias" no adquirieron el carácter de circunscripción político-administrativa de primer grado, sino la significación de áreas provinciales que funcionarían solamente a efectos de reparto de impuestos y levas militares, vehículo de comunicación de las órdenes del rey con el reino; operando, en última instancia, toda Galicia como una circunscripción provincial de primer orden en el conjunto de la Monarquía ${ }^{23}$.

A las demarcaciones de tipo administrativo en las que se dividía la Corona de Castilla en el siglo XVIII -provincias e intendencias, partidos, alcaldías mayores, gobiernos políticos y militares- cabe añadir la mencionada superposición de señoríos jurisdiccionales, sin continuidad geográfica. A mayores, la situación se complicaba en aquellos lugares en los que convivía la jurisdicción de varios señores sobre un mismo espacio. Las tierras de Ortigueira, en este sentido, resultaron un buen ejemplo, en tanto que en sus señalados $626 \mathrm{qm}^{2}$ llegaron a coexistir en el siglo XVII hasta 12 señores distintos, entre laicos y eclesiásticos. Frente a los más sonados -Astorga, Obispado

${ }^{22}$ DÁVILA DÍAZ, J. (1931). Geografia descriptiva de la comarca de Ortigueira. A Coruña: Deputación Provincial, p. 23.

${ }^{23}$ RÍO BARJA, X. (1990). Cartografia xurisdiccional de Galicia... op. cit.,pp. 10-11. 
de Mondoñedo, Casa de Alcañizas, etc.- se situaba el condado de Lemos, máximo exponente de la vieja aristocracia gallega aupada en torno a las crisis políticas de la Monarquía castellana a finales de la Edad Media que, desde la década de los 40 del siglo XVI, englobaría además la Casa de Andrade -señorío originario de las tierras de Cedeira- ${ }^{24}$ y lograría, pese a los vaivenes familiares, mantener sus estados hasta el último tercio del siglo XVIII. En el siglo objeto de análisis, señoreaba la rama de los Castro de Andrade Osorio que, además de las jurisdicciones de Cedeira, As Pontes y San Xurxo de Moeche, abarcaba -según la documentación manejada- la de Cerdido cuyo señorío, no obstante, en el siglo XVIII correspondería al Marquesado de San Sadurnino. Según datos delCatastro de Ensenada (1752), el reparto del señorío en las tierras de Ortigueira se distribuía del siguiente modo:

\begin{tabular}{|l|l|c|}
\hline \multicolumn{1}{|c|}{ Señorío } & \multicolumn{1}{|c|}{ Jurisdicciones } & $\begin{array}{c}\text { Señoreo en no de vecinos en } \\
\text { tierras de Ortigueira }\end{array}$ \\
\hline Condado de Lemos & $\begin{array}{l}\text { Cedeira, As Pontes, Cerdido (s. } \\
\text { XVII), San Xurxo de Moeche }\end{array}$ & 6.925 \\
\hline Marquesado de Astorga & Ortigueira, Mañón & 2.269 \\
\hline Casa de Alcañizas & $\begin{array}{l}\text { Galdo, Barrio de San Fiz en } \\
\text { Mogor }\end{array}$ & 316 \\
\hline Marquesado de San Saturnino & Cerdido (s. XVIII) & 202 \\
\hline Obispado de Mondoñedo & Bares, Mogor & 102 \\
\hline D. Xoaquín Velarde & Landrove & 86 \\
\hline Condado de S. Rafael & As Ribeiras do Sor & 68 \\
\hline Condado de Maceda & Santa Cruz de Moeche & No consta \\
\hline Mosteiro de Meira & As Grañas do Sor & No consta \\
\hline ColegioSeminario de Viveiro & $\begin{array}{l}\text { Coto de Malados (ínsito en } \\
\text { Cerdido) }\end{array}$ & \\
\hline
\end{tabular}

Cuadro 1: Comparativa del peso de los señoríos en las tierras de Ortigueira de acuerdo al conjunto del Reino de Galicia en número de vasallos.

FUENTE: Respuestas a la Pregunta 22aㅗ del Interrogatorio del Castastro de Ensenada según jurisdicciones de Ortigueira.

${ }^{24}$ RIVERA ROUCO, E. (1976). Estudio sobre la historia de Puentes de García Rodríguez y su comarca. A Coruña: La Voz de Galicia, p. 69. 
El señorío territorial llevaba consigo las atribuciones jurisdiccionales para la provisión de justicia a los vasallos. La jurisdicción señorial, "jurisdicción delegada", "ordinaria delegada", "especial o de privilegio" o, simplemente, "ordinaria inferior", por lo general, derivaba de una cesión, donación real o acaso de una venta, que la mayor parte de las veces comportaba, precisamente, dicha potestad de juzgar. En los reinos de la Corona de Castilla, la transferencia de máximo nivel en materia de jurisdicción vino dada por la cláusula "justicia e jurisdicción civil e criminal, alto e baxo, mero e misto ymperio", que comprendía todo el conjunto de atribuciones coercitivas del magistrado que tocaban tanto a la utilidad pública como al ejercicio de atribuciones penales, aparte de las competencias coercitivas que el juez estaba facultado a realizar para la consecución de la actividad particular. Esto es, la potestad para conocer en causas civiles y penales ${ }^{25}$. Con "mero e misto ymperio" solamente contaban en el área territorial de Ortigueira -según lo expuesto en el Catastro de Ensenada-, el Marquesado de Astorga y también el de San Sudurnino en las jurisdicciones de Mañón, Santa Cruz de Moeche y Cerdido. Mientras los señoríos circundantes gozaban de "misto imperio".

\subsection{La operatividad de los juzgados}

Sobre la carestía del mantenimiento de la justicia señorial, es parecer común en cuanto a la merma de su ejercicio a lo largo de la época moderna. Básicamente, la desarticulación del señorío jurisdiccional vendría dada por su inactividad después de que la Real Audiencia hubiese sido asentada en la ciudad de A Coruña en 1563. Ciertamente, se desconoce por el momento la operatividad de la totalidad de juzgados para las 665 jurisdicciones y cotos redondos de la Galicia moderna ${ }^{26}$. Sin embargo, el análisis del fondo judicial de los tribunales del área de Ortigueira en el siglo XVII, en complemento con la consulta del Interrogatorio del Marqués de Ensenada para el siglo posterior, confirma el funcionamiento continuo de la justicia ordinaria ortigueiresa en Antiguo Régimen, incluso en los cotos de menor entidad. De tal forma que hacia 1752 en Cerdido y Malados se notifica la presencia de,

"un Juez de estte coto de Cerdido que lo es Pedro de villar que como tal Administra Justicia en el y le consideran utiliza al año trescientos Reales de vellon y a Antonio Fernandez de Herva escribano de su Magestad como tal escribano le rregulan de utilidad en cada un año un mil y cien Reales, y por lo que respecta al Juez de dicho coto

\footnotetext{
${ }^{25}$ LÓPEZ DÍAZ, M. (2006). "La administración de la justicia señorial en el Antiguo Régimen”. AHDE, LXXVI, pp. 559-583.

${ }^{26}$ EIRAS ROEL, A. (1989). "El señorío gallego en cifras: nómina y ranking de los señores jurisdiccionales". Cuadernos de Estudios Gallegos, 103, p. 131.
} 
de Malados, aunque es vezino de la villa de Vivero le rregulan de utilidad cien Reales de vellon" 27 .

En tanto que en Galdo, "hay un Juez ordinario que es Juan de Pedrosa, que administra Justicia en la jurisdicion de Galdo y demasfeligresias sufragáneas"28. Éste, recibía por su oficio 400 reales de vellón al año, junto con un escribano, José Rodríguez quien, por su parte, cobraba 1.500 reales. En Mogor y Bares había "un escribano de numero de la Jurisdicion de Barias, y esta sufraganea a ella, que lo es Pedro de Galdo"29. Percibía 1.100 reales al año, mientras que el teniente de juez ordinario recibía anualmente 100 reales de vellón. En Landrove, Pedro da Seara, teniente de juez ordinario, tenía estipendio de 44 reales "por ser el vecindario reducido" 30,24 reales su ministro y Antonio Rodríguez, escribano de Su Magestad, 1.650 reales $^{31}$.

Al contrario de la común opinión, parece por lo tanto que ni el corto número de vecinos ni lo reducido del territorio del señorío obró en contra de la provisión de justicia. Las fuentes judiciales manejadas para el siglo anterior al Catastro de Ensenada (XVII), corroboran la operatividad en el tiempo de jueces independientes en aquellas unidades jurisdiccionales menores. De hecho, los jueces de Santa Marta de Ortigueira ni siquiera coinciden con los de Mañón - de la misma titularidad señorial-, como tampoco coinciden entre sí los de Cedeira y Cerdido. En un número muy inferior al de los tribunales anteriores, se encontraron en el muestreo causas concernientes a las jurisdicciones de San Cristovo das Ribeiras do Sor, San Mamede das Grañas do Sor, San Fiz de Roupar y Santiago Sere das Somozas - dentro del territorio concerniente al coto de Cabalar, ínsito en Cerdido-, también sin coincidencia de sus jueces con ninguno de los señoríos mayores.

De hecho, en el pleito de partija llevado a cabo entre noviembre de 1637 y septiembre de 1642 en la parroquia de Grañas do Sor se indica la intervención de juez propio: "En el coto de las granas a siete dias del mes de hebrero de mil y seiscientos treinta y ocho anos ante su merced Juan de castro merino en el dicho coto" 32 . Y lo mismo con respecto a un ejemplo de partija y separación de bienes habida en San Cristovo das Ribeiras do Sor: "En la dicha feligresia de ssancriptobal de las Riveras del ssor a los dichos catorçedias de dicho mes de septiembre de dicho año de mil y sseiscientos

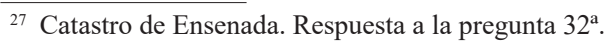

28 Ibid.

29 Ibid.

30 Ibid.

31 Ibid.

${ }^{32}$ AHUS, serie judicial civil, Ortigueira, Exp. 128.
} 
y ssessenta y cinco ante su merced antonio de oca Juez hordinarioen la Jurisdicion civil y hordinaria en dicha feligresia de las Riveras y su Jurisdicion"33. Hasta en la pequeña franja territorial entre los cotos de Malados y Cabalar se encuentra una causa de cuentas de partija ante un juez propio: "Visto el pedimento y masdeligencias de atras por su merced don francisco diaz De Cora, alcalde y Justiçiahordinaria en este quarto de Cavalarfeligresia de Santiago de Sere de las Somoças en el, a ocho dias del mes de henero del año de mil y seiscientos y ochenta y dos"34.

Ciertamente, aunque muy reducido el número de causas en estas pequeñas jurisdicciones, más que a una posible inactividad de sus tribunales, sin duda esto se debe a una falta de conservación de los expedientes respectivos a los juzgados de estos pequeños señoríos. Puesto de manifiesto lo anterior, cabe preguntarse sin embargo qué ha podido suceder con la documentación judicial perteneciente a Galdo, Landrove y jurisdicciones -igualmente, encuadradas en el espacio geográfico ortigueirés- cuyos expedientes, sin embargo, no se han podido hallar. De nuevo, la primera sospecha giraría en torno a la inactividad. No obstante, comprobada la operatividad de dichos tribunales, esto no semeja de todo plausible. Antes de concluir nada, cabría formularse por qué acaso ha llegado a la actualidad en bloque la documentación respectiva a los señoríos conformantes de la comarca de Ortigueira, incluso dos siglos antes de su constitución como partido judicial. En este punto, acudir a los jueces ya tampoco aportaría respuesta satisfactoria. Más bien, se deduce, la clave radicaría en los escribanos. Pues eran estos oficiales -y no los jueces- quienes controlaban las fases y pautas del proceso en los juzgados de señorío. En consecuencia, también se encargaban del custodio de la documentación, judicial y notarial. Poseían archivo en su casa donde, careciendo la jurisdicción de lugar de audiencia, podrían celebrarse los juicios. Así pues, aunque no haya coincidencia entre los nombres del jueces del área de Ortigueira, sí la hay de los escribanos en tres áreas: Cedeira/Cerdido, As Grañas/Ribeiras do Sor/ Mogor y Bares, As Pontes/Roupar.

De los 13 escribanos que caen dentro del muestreo temporal realizado, hay cinco que llevan un solo señorío, en cuanto los restantes ocho cubren varias jurisdicciones. Unas veces coinciden las áreas de ejercicio de los escribanos tal cómo vienen siendo trazadas, mientras que otras veces se mezclan jurisdicciones de áreas distintas. El tránsito de escribanos a lo largo y ancho de las jurisdicciones de Ortigueira, lejos de cuestionar esa falta de unidad administrativa en Antiguo Régimen, muestra que

\footnotetext{
33 AHUS, serie judicial civil, Ortigueira, Exp. 152.

${ }^{34}$ AHUS, serie judicial civil, Ortigueira, Exp. 1.073.
} 
la relación entre las mismas derivaba únicamente de la proximidad geográfica, no administrativa.

\begin{tabular}{|l|c|l|}
\hline \multicolumn{1}{|c|}{ Escribano } & $\begin{array}{c}\text { Fechas de } \\
\text { ejercicio }\end{array}$ & \multicolumn{1}{|c|}{ Jurisdicciones cubiertas } \\
\hline SÁNCHEZ, Juan & $1619-1673$ & Cedeira y Cerdido \\
\hline PITA BASSOA, Pedro & 1630 & Santa María de Ortigueira \\
\hline GARCÍA DE PINHEIRO, Nicolás & $1633-1666$ & $\begin{array}{l}\text { Ortigueira, Mogor, Bares y San Cristovo } \\
\text { das Ribeiras do Sor }\end{array}$ \\
\hline FERNÁNDEZ DAPENA, Luis & 1637 & Granhas do Sor y Cedeira \\
\hline DAREAL, Juan & $1655-1685$ & Cedeira y As Pontes \\
\hline CORTÉS, Antonio & $1656-1691$ & Santa Marta de Ortigueira \\
\hline FREIRE DE ANDRADE, Bernabé & $1665-1693$ & $\begin{array}{l}\text { Ortigueira, As Granhas, Mogor, Bares y } \\
\text { As Ribeiras do Sor }\end{array}$ \\
\hline PÉREZ SOLLOSO, Francisco & $1665-1689$ & As Pontes y Roupar \\
\hline PEÑA Y VAAMONDE, Juan de la & 1666 & As Pontes \\
\hline DUTÓN, Andrés & $1668-1675$ & Santa Marta de Ortigueira \\
\hline LAGO, Pedro de & $1680-1735$ & Cedeira \\
\hline $\begin{array}{l}\text { DÍAZ DE PARGA Y SAAVEDRA, } \\
\text { Fernando }\end{array}$ & $1681-1682$ & Santa Marta de Ortigueira \\
\hline PEÑA Y PARGA, Juan de la & $1681-1725$ & Santa Marta de Ortigueira \\
\hline
\end{tabular}

Cuadro 2: Escribanos por fechas de ejercicio y jurisdicciones.

FUENTE: AHUS, serie judicial civil, Ortigueira, Exp. 1- 1234.

\subsection{LAS CAUSAS}

\subsection{Tipología}

Los jueces operantes en el área de Ortigueira lo eran en primera instancia. En Galicia sucede algo distinto al Reino de Portugal, donde la justicia señorial funcionaba como intermediaria y cabía la posibilidad de recurso de los jueces de la tierras al juez u oidor nombrado por el señor jurisdiccional, si éste tuviere derecho a hacerlo ${ }^{35}$. Quiere decirse con esto que, a diferencia de Portugal, las jurisdicciones gallegas se

\footnotetext{
${ }^{35}$ Cosa que en Galicia no suele funcionar así, salvo ejemplos concretos del Juez Asistente de Santiago y el obispo de
} 
encontraban al mismo nivel dentro del Ordenamiento Jurídico, por lo que no tendría lugar la apelación entre audiencias de entes poblacionales pertenecientes al mismo señor. De hecho, los rastreos de apelación seguidos en los juzgados de Ortigueira conducen, directamente, a la Real Audiencia, sin posibilidad, por ejemplo, de recurrir un auto dado por el juez de Mañón en la audiencia de Santa Marta de Ortigueira. Todo esto parece indicar que, pese a la innegable confianza mostrada en "la fuente limpia de justicia", la gente utilizaba los juzgados señoriales -y los utilizaba con asiduidaden toda aquella serie de causas que, por escasa cuantía o razones de índole procesal, no pudiesen ser iniciadas en la Audiencia de Galicia. A saber, partijas de herencia entre partes de la misma jurisdicción, curadorías y representación -obligatoriamente, a resolver en primera instancia- y deudas de menos de 10.000 maravedís $^{36}$. Entre la escasa- variedad tipológica se pueden encontrar, además, retractos y recobros de bienes raíces, amén de causas de índole pública -tales como mandatos del señor jurisdiccional, órdenes de autoridades del Reino, solicitudes a título particular al regimiento o juzgado y pleitos pendientes de la villa de Ortigueira con otras villas y jurisdicciones gallegas-, más una serie de asuntos no agrupados que, en su mayoría, se relacionan con bienes raíces y patrimoniales. En porcentajes, el reparto causal vendría a ser el que sigue:

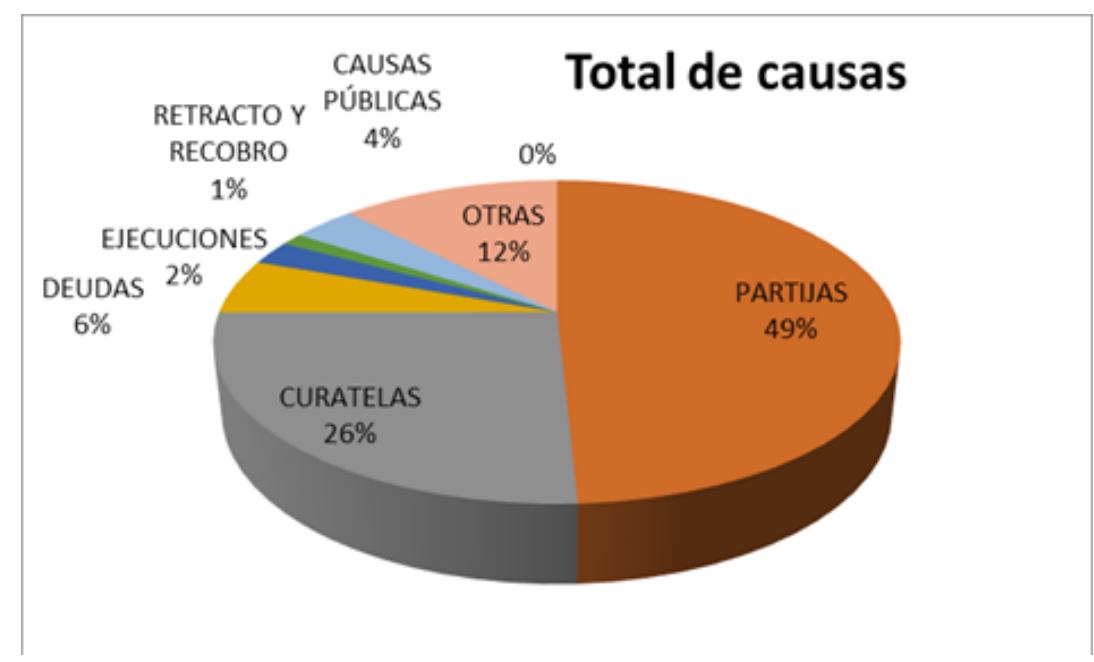

Gráfica 1.

FUENTE: AHUS, serie judicial civil, Ortigueira, Exp. 1- 1.234.

Tui, con facultad de recurrir las sentencias emitidas por las justicias de sus respectivas tierras. Cfr. GONZÁLEZ FERNÁNDEZ, X. M. (1997). La conflictividad judicial ordinaria ... op., cit., con HESPANHA BOTELHO, A. M. (1994). As vésperas do Leviathan: Instituiçoes e poder político em Portugal. Séc. XVII. Lisboa: Almedina, p. 482.

${ }^{36}$ Herbella DE PUGA, B. (1768). Derecho práctico i estilos de la Real Audiencia de Galicia. Santiago de Compostela: Imprenta de Ignacio Aguayo, p. 2. 
De la litigiosidad experimentada se infiere una sociedad poco dinámica en la que el apego a la tierra conlleva, además, el sello de la familia para unas gentes que, desaparecidos los causabientes, debían disponer de los bienes atendiendo a un sistema de herencia mayoritariamente desigualitario y con tendencia a la mejora corta. El hecho de coexistir hijos de sucesivos matrimonios -según la lógica de un mercado matrimonial en el que proliferaban las segundas nupcias en ambos sexos-, ya de inicio hacía prever disputas con hermanos, hermanastros, madrastras o padrastros lo cual, previsiblemente, trataba de ser solventado mediante el recurso -caro, aunque efectivo en términos legales- de la partija de herencia. Al mismo tiempo, solían quedar descendientes menores de 25 años o emigrados -sobre todo, en zonas de alta emigración estacional, como Ortigueira y As Pontes- a los que era necesario proveer de curador y cuya gestión habría que fiscalizar una vez extinta la relación, mediante tasación hecha por "expertos" locales -"hombres-buenos, contadores, partidores, tasadores y "abaliadores"- con refrendo judicial final. La presencia de la tierra, dotada de tan fuerte componente familiar se nota, igualmente, en las acciones de retracto interpuestas contra aquellos propietarios que, lejos de respetar el derecho de adquisición preferente que tocase a sus coherederos, vendían los inmuebles sin ejercer tanteo ni consentimiento - pues el Ordenamiento Jurídico prohibía el retracto de muebles, a excepción de las armas-. La tierra, "fuente inagotable de conflictos" ${ }^{37}$, se enmarca de nuevo en la categoría "otros" bajo la forma de reclamación de rentas, foros, propiedad, posesión, partición de montes y alguna -minoritaria y fuera del muestreo- servidumbre. Es dentro de esta última categoría donde se engloban los escasos asuntos de mar, reflejo de un medio económico en decadencia a lo largo del siglo XVII (0,72\%). Las deudas, por su parte, constituyeron el único sector de litigiosidad con predominio de la reclamación intercomunitaria frente a la familiar.

\subsection{Evolución de la litigiosidad a lo largo del siglo XVII}

Analizadas las tipologías, corresponde ahora hablar de volúmenes de causas tramitadas por juzgado. En lo que a diferencias cuantitativas se refiere, obviamente resultan los tribunales de las villas los que recogen mayor carga de trabajo por razones que atienden al número de vecinos. Pero esto no desdibuja la aparición en escena de las audiencias de jurisdicciones uniparroquiales, con índices inferiores, aunque significativos. En cuanto a la casi totalidad de las causas, no se aprecia variación tipológica notable según juzgado. De modo que los asuntos que requieren de la facultad de refrendo, más que arbitrio judicial, son los recurrentes: recuentos

${ }^{37}$ GONZÁLEZ FERNÁNDEZ, X. M. (1997). La conflictividad judicial ordinaria ... op., cit., p. 100. 
y repartos de herencias, designación de curadores y emancipaciones de menores. Si bien, un mayor o menor número de vecinos supondría un indicio claro en cuanto al incremento del número de asuntos por audiencia señorial, cabe tener en cuenta que el XVII resulta un siglo marcado por las pérdidas documentales en los archivos gallegos. Aun constituyendo el de Ortigueira un fondo extraordinario, también en él se detectan ciertas lagunas. No obstante, éstas no llegan a afectar la representatividad casuística. Dichas lagunas documentales se detectan, sobre todo, durante las primeras décadas del siglo, puesto que se va produciendo un incremento del número de expedientes a medida que va avanzando el tiempo. El cual se percibe de forma desigual según el conjunto de los juzgados: desde los 48 casos hallados en la primera fase de muestreo, a los 129 de la segunda y, así, hasta sumar 417. Pero, las pérdidas no afectan de manera uniforme a los juzgados, ni respectan -por separado- los períodos que se presuponen de repunte de la litigiosidad -conforme se aproximaría el siglo XVIII-:

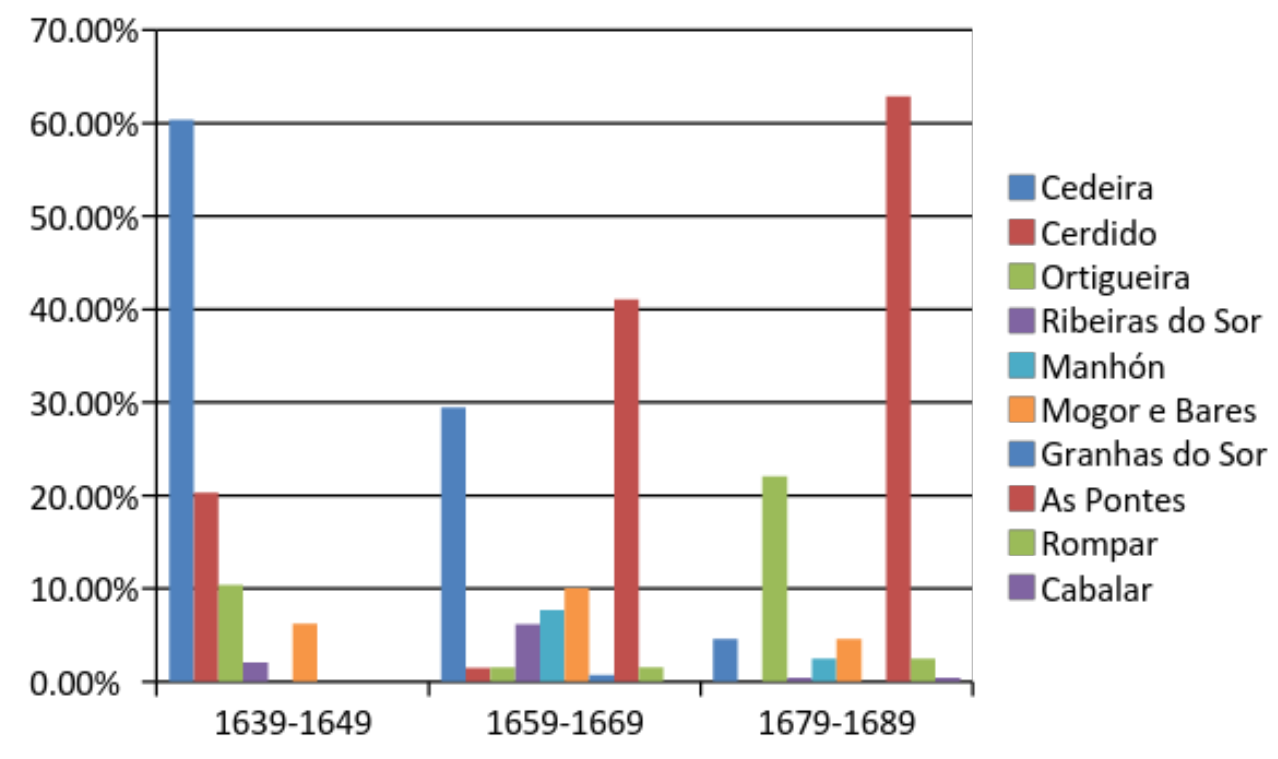

Gráfica 2. Evolución porcentual de la actividad por juzgado a lo largo del siglo XVII. FUENTE: AHUS, serie judicial civil, Ortigueira, Exp. 1- 1.234.

En esa tendencia al alza de conservación documental, a medida que avanza el Antiguo Régimen resulta difícil de explicar -sino con base en pérdidas- la acusada merma de actividad en los juzgados de las villas de Cedeira y Ortigueira, frente a la irrupción de As Pontes en la segunda fase de muestreo -inexistente en el período 
1639/49-. Lo mismo y en idéntica franja cronológica ocurre con Mañón que, a pesar de no encontrarse presente en 1639/49, emerge con un volumen notable en 1659/69 para desaparecer en el último tercio del siglo -justo cuando el volumen documental se dispara-. As Ribeiras do Sor, que experimenta un leve aumento del primer al segundo muestreo, también cae al $0 \%$ a finales de siglo. En este sentido, el caso de Cerdido resulta flagrante, tratándose de un juzgado que inicia la centuria con fuerza y mengua repentinamente entre 1659/69. Jurisdicciones uniparroquiales y cotos ínsitos en otros, como As Grañas do Sor, Roupar y Cabalar, no debieron de experimentar gran variación de número de casos en volúmenes de por sí pequeños. Dentro de lo que a cifras modestas se refiere, fue la de Mogor y Bares la única jurisdicción en mantenerse -a pesar de una sospechosa mengua de causas en el muestreo final-. En número y porcentaje por audiencia:

\begin{tabular}{|c|c|c|c|c|c|c|c|c|c|c|c|c|c|c|}
\hline & \multicolumn{2}{|c|}{ Partijas } & \multicolumn{2}{|c|}{ Curatelas } & \multicolumn{2}{|c|}{ Deudas } & \multicolumn{2}{|c|}{ Ejecuciones } & \multicolumn{2}{|c|}{ Retractos } & \multicolumn{2}{|c|}{ C/Pcas } & \multicolumn{2}{|c|}{ Otros } \\
\hline & $\mathrm{No}^{\circ}$ & $\%$ & No & $\%$ & No & $\%$ & $\mathrm{~N}^{\circ}$ & $\%$ & No & $\%$ & No & $\%$ & No & $\%$ \\
\hline Cedeira & 58 & 13,9 & 11 & 2,64 & 1 & 0,24 & 1 & 0,24 & 1 & 0,24 & 0 & 0 & 7 & 1,68 \\
\hline Cerdido & 10 & 2,4 & 11 & 2,64 & 1 & 0,24 & 0 & 0 & 0 & 0 & 0 & 0 & 1 & 0,24 \\
\hline $\begin{array}{l}\text { Ribeiras do } \\
\text { Sor }\end{array}$ & 4 & 0,96 & 0 & 0 & 3 & 0,71 & 0 & 0 & 0 & 0 & 0 & 0 & 3 & 0,71 \\
\hline Manhón & 9 & 2,15 & 0 & 0 & 3 & 0,71 & 0 & 0 & 0 & 0 & 1 & 0,24 & 1 & 0,24 \\
\hline $\begin{array}{l}\text { Mogor y } \\
\text { Bares }\end{array}$ & 6 & 1,44 & 2 & 0,48 & 4 & 0,96 & 1 & 0,24 & 2 & 0,48 & 2 & 0,48 & 9 & 2,16 \\
\hline $\begin{array}{l}\text { Granhas do } \\
\text { Sor }\end{array}$ & 0 & 0 & 0 & 0 & 0 & 0 & 0 & 0 & 0 & 0 & 0 & 0 & 1 & 0,24 \\
\hline Ortigueira & 8 & 1,91 & 4 & 0,96 & 10 & 2,4 & 5 & 1,2 & 2 & 0,48 & 14 & 3,38 & 18 & 4,32 \\
\hline As Pontes & 99 & 23,75 & 90 & 21,58 & 1 & 0,24 & 2 & 0,48 & 0 & 0 & 0 & 0 & 12 & 2,88 \\
\hline Roupar & 5 & 1,2 & 3 & 0,72 & 0 & 0 & 0 & 0 & 0 & 0 & 0 & 0 & 0 & 0 \\
\hline $\begin{array}{l}\text { Coto de } \\
\text { Cabalar }\end{array}$ & 1 & 0,24 & 0 & 0 & 0 & 0 & 0 & 0 & 0 & 0 & 0 & 0 & 0 & 0 \\
\hline
\end{tabular}

Cuadro 3. Tipologías de causas por juzgados con sus totales.

FUENTE: AHUS, serie judicial civil, Ortigueira, Exp. 1-1.234.

Se comprueba de nuevo cómo los asuntos de familia copan el quehacer diario de los juzgados, especialmente, en As Pontes de García Rodríguez -189 expedientes-, al contrario de las demás categorías, parcas en ejemplos o sin ninguno. En el término medio, y siempre dentro de lo modesto de sus cifras, se sitúan Mogor y Bares, con la particularidad de ver todas las categorías representadas. Por su parte, las causas 
públicas se llevan el porcentaje más importante en Ortigueira, juzgado en comunión con el regimiento municipal, tan pendiente de las honras a la Casa de Astorga como de los mandatos provenientes de las autoridades del Reino. Aunque el porcentaje general de partijas encontradas cae en 10 puntos entre los períodos $1639 / 49$ y $1679 / 89$, en cambio se cuantifica en un $15 \%$ el incremento de los expedientes por asuntos derivados de la representación personal. Así pues, la familia se mantiene a la cabeza de la litigiosidad, seguida de la variedad de asuntos patrimoniales contenidos en la categoría "otros": desde la división de fincas y reclamaciones por herencia, a los desacuerdos por derechos reales, desalojos de inmuebles, construcciones en fincas ajenas y documentación notarial desparramada, entre otros asuntos. Por su parte, las deudas resultan irrisorias, ya que -ejecuciones incluidas- en ningún caso superan el $10 \%$ de las causas muestreadas. Llama la atención la escasa entidad de esta tipología pues, aunque se encuentra presente en la casi totalidad de juzgados, representa una cantidad muy baja para el conjunto de un siglo. En los cotos redondos, la representatividad de las causas elevadas también suele ir de la mano de la litigiosidad familiar, a excepción de As Grañas do Sor, en donde no aparece estrictamente ningún asunto de partijas ni curadorías, pero sí un pleito sobre posesión de bienes hereditarios.

El peso patrimonial de los asuntos erigidos estriba en la existencia de estructuras familiares que aproximan el sistema hereditario del área geográfica de Ortigueira al de la Galicia costera occidental, basado en el predominio de la familia de tipo nuclear, así como en la abundancia de hogares de solitarios y la cesión hereditaria a través de la mejora corta. Por otra parte, la presencia de montes abiertos en la zona -o de goce común-, además del retraso en la implantación del maíz en unos 80 años en esta franja norte con respecto a la Galicia atlántica ${ }^{38}$, contribuyeron a mantener la litigiosidad entre las familias que, derivándose del cercado de parcelas, en otras áreas geográficas gallegas tendió a explosionar entre vecinos. A tales efectos, resulta indicativa la escasez 0 práctica inexistencia de causas por servidumbre. El policultivo de cereales tradicionales con el maíz no emitiría, pues, especial variación en la tipología causal de unos litigios que, aún con ciertos matices según qué juzgado (Ver cuadro 2), mantendrían la tónica general descrita a lo largo de la Edad Moderna. De igual forma, el escaso dinamismo económico de esta área, que motiva los propios intereses de los litigantes, muestra nueva razón en cuanto al predominio de los asuntos patrimoniales y de administración de personas y bienes sobre otras causas civiles -deudas, servidumbres, propiedad y derechos reales-. En índice de causas por juzgado y período de muestreo:

${ }_{38}$ SAAVEDRA FERNÁNDEZ, P. (1985). Economía, Política y Sociedad en Galicia ... op., cit., 174-175. 


\begin{tabular}{|l|c|c|c|c|c|c|}
\cline { 2 - 7 } \multicolumn{1}{c|}{} & \multicolumn{2}{c|}{$\mathbf{1 6 3 9 / 1 6 4 9}$} & \multicolumn{2}{c|}{$\mathbf{1 6 5 9 / 1 6 6 9}$} & \multicolumn{2}{c|}{$\mathbf{1 6 7 9 / 1 6 8 9}$} \\
\hline Asuntos & $\mathbf{N}$ & $\mathbf{0}$ & $\mathbf{N}$ & $\mathbf{N}$ & $\mathbf{N}^{\mathbf{0}}$ & \% \\
\hline FAMILIARES & & & & & & \\
\hline Partijas & 26 & 54,16 & 68 & 52,71 & 106 & 44,16 \\
\hline Curatelas & 7 & 14,58 & 27 & 20,93 & 73 & 30,41 \\
\hline ECONÓMICOS & & & & & & \\
\hline Deudas & 2 & 4,16 & 6 & 4,65 & 15 & 6,25 \\
\hline Ejecuciones & 2 & 4,16 & 1 & 0,77 & 7 & 2,91 \\
\hline RETRACTOS & 1 & 2,08 & 1 & 0,77 & 3 & 1,25 \\
\hline CAUSAS PCAS & 0 & & 2 & 1,55 & 13 & 5,42 \\
\hline OTROS & 10 & 20,83 & 22 & 17,05 & 19 & 7,92 \\
\hline Totales & $\mathbf{4 8}$ & & $\mathbf{1 2 9}$ & & $\mathbf{2 4 0}$ & \\
\hline
\end{tabular}

Cuadro 4. Volumen de causas por períodos

AHUS: serie judicial civil, Ortigueira, Exp. 1-1.234.

Así pues, las operaciones movidas alrededor de la división del patrimonio tras la muerte de los petrucios devienen las causas más propicias para el nacimiento y desarrollo de posteriores enfrentamientos por la propiedad de los bienes familiares. Los cuales no necesariamente se tendrían que llevar a cabo inmediatamente al deceso del causante, sino que podían transcurrir años e incluso décadas por medio. Todo redunda en lo costoso que resultaba poner en marcha un pleito -en sentido amplio-, por lo que los demandantes esperarían al momento más propicio para imponer una reclamación. La mayor parte de las veces, esto tendría lugar entre hermanos -menos frecuentes las interpuestas entre el resto de colaterales-, a pesar de observarse también cantidad de casos de hijos reclamando contra la madrastra, el padrastro o su propio progenitor supérstite. En consecuencia, el predominio de la familia nuclear con sistema de herencia de mejora corta generaba arduas discusiones sobre la propiedad de los bienes hereditarios.

Por otra parte, a modo de comparación, en sus análisis sobre la litigiosidad familiar dirimida ante la Real Audiencia de Galicia, Isidro Dubert no halla diferencia entre el porcentaje de partijas procedentes de la Galicia occidental (26,9\%) y las de la Galicia oriental $(26,1 \%)$, donde es sistema de herencia es troncal ${ }^{39}$. Si bien es cierto que se trata de una instancia procesal superior a los juzgados de señorío, los cuales recibían la mayoría de las causas de la litigiosidad cotidiana. En idéntico orden de cosas, el maíz vendría a constituir, en la generalidad gallega, el factor habilitante para el inicio de causas, en el sentido de producir los excedentes económicos que, entonces, podrían

${ }_{39}$ DUBERT GARCÍA, I. (1990). Historia de la familia en Galicia durante la época moderna... op., cit., pp. $328-329$. 
desviarse al pago de la justicia. Según los mismos estudios de Isidro Dubert, mediado el siglo XVII, se abriría una fase de 20 años (1660-1680) correspondiente al repunte de la litigiosidad derivada de las partijas de herencia con base en la fragmentación de las explotaciones, debido a la introducción de los nuevos cultivos que, al contrario de la justicia de la Audiencia, parece no afectar a los juzgados ortigueireses ${ }^{40}$. Como tampoco aturdiría su actividad la recesión económica de los años 80 del mismo siglo, ni el crecimiento poblacional, manteniéndose por lo tanto la misma línea de causas en la centuria siguiente.

\subsection{La resolución de las causas}

No todas las causas erigidas ante los juzgados de Ortigueira terminaron en juicio, ni siquiera un tercio de ellas. La mayor parte, bien por su naturaleza -cuando no exigían auto judicial-, bien por el incompleto de los expedientes o la carestía de los procesos -lo cual solía animar a los litigantes a la celebración de acuerdos parajudiciales-, fenece en trámites intermedios del proceso, anteriores a la celebración del juicio propiamente dicho o la emisión de auto judicial. Por eso, prefiere hablarse en la presente investigación de "causas" o "asuntos" para denominar genéricamente toda esta variedad tipológica y procesal, cuya tramitación resulta susceptible de estructurarse en las siguientes fases:

\begin{tabular}{|c|c|c|c|c|c|c|c|}
\hline & & No & $\%$ & & & No & $\%$ \\
\hline \multirow{5}{*}{ PARTIJAS } & Total & 200 & 47,96 & \multirow{5}{*}{ CURATELAS } & Total & 107 & 25,66 \\
\hline & Pedimentos & 38 & 9,11 & & Pedimentos & 69 & 16,55 \\
\hline & Partijas & 112 & 26,86 & & Rendiciones & 7 & 1,68 \\
\hline & Recuentos & 57 & 13,7 & & Pleitos & 2 & 0,48 \\
\hline & Pleitos & 13 & 3,12 & & Cap./Emac. & 31 & 7,43 \\
\hline & & & & & & & \\
\hline \multirow{3}{*}{ DEUDAS } & Total & 23 & 5,52 & \multirow{3}{*}{ EJECUCIONES } & Total & 10 & 2,4 \\
\hline & Reclamaciones & 20 & 4,8 & & Pedimentos & 1 & 0,24 \\
\hline & Pleitos & 4 & 0,96 & & Pleitos & 8 & 1,92 \\
\hline RETRACTOS & Total & 5 & 1,2 & C./PCA & Total & 17 & 4,08 \\
\hline OTROS & Total & 50 & 12 & & & & \\
\hline
\end{tabular}

Cuadro 5. Índice de litigios según fase procesal de conclusión.

* Capacidad/emancipación, exclusivamente solicitadas a nivel judicial en As Pontes de García Rodríguez y coto ínsito de Roupar.

${ }^{40}$ Ibid., pp. 330-331. 
En variedad tipológica de trámites, destacan las partijas -con pedimentos, partijas en sentido estricto, recuentos y pleitos- y las curadorías - con idénticos trámites, más capacidad y emancipación, exclusivas en As Pontes y Roupar-. Como puede observarse, se trata -en la mayor parte de los casos- de una actuación judicial leve -de refrendo- que asemejaría el quehacer judicial a la función notarial. Nótese también que la clasificación tipológica ha sido realizada conforme a criterios archivísticos. De modo que, supuestos frecuentes en los que se englobaría una partija con pedimento, recuento y partición, se ha optado por su clasificación en la categoría que subsume a las demás -en este caso, "partija"-. Lo mismo ocurre en cuanto a tutorías y curatelas, grupo que se encontraría menguado en los cuadros hallándose, una buena parte de ellas, incluídas dentro de las propias partijas. Más sencillo se ha vuelto el asunto de las reclamaciones por deudas y ejecuciones, en el que se reservan para el apartado "pleitos" solamente aquellos asuntos que requirieron de vista ante el juez. Mientras que la natureza de las "causas públicas" no permite agrupar según fases procesales.

Se está, pues, ante una sociedad que acudía asiduamente a unos juzgados en los que se "actuaba" mucho y, sin embargo, se pleiteaba poco. Los datos vienen a reforzar esa función primordial de los jueces de señorío de "ajustar", "concordar" e, incluso, "gobernar" la comunidad ${ }^{41}$, a la de juzgar en derecho, la cual se reservaba a los letrados de audiencias reales y chancillerías. Así, el 16\% de los pleitos y causas concluye sin auto.

\subsection{El coste de la justicia en tiempo y dinero}

A la visión de la escasa rapidez de la justicia gallega en el Antiguo Régimen cabría responder con varias matizaciones. En primer lugar, habría que distinguir entre los juzgados locales de primera instancia -junto con algunas alcaldías mayores con capacidad para recibir apelaciones- y los altos tribunales de la monarquía -audiencias, chancillerías y consejos-, con diferencias no solamente establecidas en el orden jurídico o social, sino también en lo económico, así como en la propia celeridad de las resoluciones. La mayor enjundia que solían tener los asuntos elevados a los tribunales de la monarquía frente a aquellos que fenecían en el señorío supondría, en parte, justificación de la "paciencia" que Richard Kagan atribuyó a los litigantes exitosos en la Corona de Castilla ${ }^{42}$. Una concepción sobre la lentitud de la justicia

${ }^{41}$ SAAVEDRA FERNÁNDEZ. P. (1990). “Contribución al estudio del régimen señorial gallego”. AHDE, LX, pp. 167-168.

42 "In addition to skill in manipulating court officials, a successful litigant in a Castilian court had to be able to wait. Civil justice normally moved at slow, lethargic pace, and complaints about the 'lentgth of the lawsuits' and 'immortal lawsuits' cropped up repeatedly in the Cortes, in private correspondence, and in literature". KAGAN, R. (1981). Lawsuits and litigants in Castile: 1500-1700, Chapel Hill: The University of North Carolina, p. 42. 
que, aun transmitida por las élites, era compartida por los estratos sociales más bajos. Convirtiéndose, por lo tanto, en el argumento más socorrido para la celebración de convenios.

Ahora bien, en términos comparativos, poco tenían que ver los asuntos que se resolvían en las reales audiencias con los que finalizaban en el señorío en cuanto a materia y tiempo ${ }^{43}$. Especialmente, al comprobar que en la primera instancia ortigueiresa la mitad de los asuntos se resolvió antes de los seis meses, en tanto que a penas un 8\% llegó a los dos años de duración.

\begin{tabular}{|l|c|c|}
\cline { 2 - 3 } \multicolumn{1}{c|}{} & Número & Porcentaje \\
\hline Inmediata (-1 mes) & 159 & 42,63 \\
\hline $\mathbf{1}$ y 3 meses & 25 & 6,07 \\
\hline 3 y 6 meses & 11 & 2,95 \\
\hline 6 y 12 meses & 12 & 3,22 \\
\hline 1 año / año y medio & 28 & 7,5 \\
\hline 1 y 3 años & 9 & 2,41 \\
\hline 3 y 6 años & 3 & 0,8 \\
\hline 6 - 10 años & 3 & 0,8 \\
\hline + 10 años & 5 & 1,34 \\
\hline
\end{tabular}

Cuadro ${ }^{44}$. Tiempo de duración de los litigios

FUENTE: AHUS, serie judicial civil, Ortigueira, Exp. 1-1234.

La explicación sobre la resolución cuasi inmediata de poco menos que la mitad de causas se debe, en buena medida, a la actividad llevada a cabo en el juzgado de As Pontes de García Rodríguez y coto ínsito de Roupar, dada la naturaleza de los asuntos allí elevados -recuentos de bienes, emancipaciones de menores-, que exigía una resolución expedita. En idéntico orden de cosas, el porcentaje de litigios solventados antes de los dos años, superior incluso al de la audiencia rural de Bouzas estudiada por Xoán Miguel González Fernández, sobrepasa la mitad de lo escrutado (62,37\%) que, a mayores de los recuentos, supondría un $12,24 \%$ de casos resueltos antes de un año.

\footnotetext{
43 Acudiendo otra vez a las investigaciones de Xoán Miguel González Fernández sobre la pequeña audiencia rural de Bouzas, se observa un reparto homogéneo en la duración de las causas hasta la cuota de dos años -entre el 15 y el $18 \%$ de los litigios-, para reducirse gradualmente hasta sobrepasar, rara vez, los cuatro años de duración. Mientas que en la audiencia del Asistente de Santiago, uno de cada tres litigos era solventado antes de seis meses. En GONZÁLEZ FERNÁNDEZ, X. M. (1997). La conflictividad judicial ordinaria ... op., cit., p. 48.

${ }^{44}$ Excluida la documentación notarial.
} 
La razón de dicha celeridad viene debida, en parte, a la sencillez de las causas elevadas a los juzgados ortigueireses, que no iban más allá de las partijas de bienes, el cobro de deudas y algún retracto, dependientes en una mayor medida de la voluntad de las partes que del arbitrio judicial en acelerar o retardar el litigio. No merecería la pena establecer aquí una clasificación sobre duración de causas según materia, pues no se aprecian diferencias en relación al tiempo de resolución.

En nada tuvo que ver la prolongación en el tiempo con los trámites procesales -las notificaciones y expediciones documentales se iban realizando en un plazo de tres días contados desde la petición-, sino con las continuas alegaciones de las partes. Documentándose, incluso, el caso de una partija que duró 76 años, seguida de otras dos de 11 y 12 años, respectivamente. Con lo que de las cifras se extrae la tardanza relativa en la resolución de los asuntos a nivel local, lo cual coincide con lo estudiado por Xoán Miguel González Fernández y matiza esa visión tópica de la lentitud de la justicia que, en buena medida, pudo venir dada por el concepto de tiempo que tenía la gente en Antiguo Régimen. Especialmente en el mundo rural, donde existían unos ciclos agrarios muy marcados. Por otra parte, entra dentro de lo posible que, para una persona del pueblo, resultase inasumible mantener un pleito más de un año, ya no solo debido al tiempo empleado en gestiones y comparecencias, sino por el coste económico, teniendo en cuenta sus casi siempre limitados recursos ${ }^{45}$.

Respecto a los costes de la justicia, desgraciadamente los escribanos ortigueireses -como tantos otros- incumplieron la obligatoriedad de asentar y firmar en los procesos las cantidades legalmente establecidas, lo que lleva a sospechar del incumplimiento de las mismas, por lo menos durante el siglo XVI. De ahí que, en este aspecto, solo se pueda recurrir a los estudios preexistentes. Sobre el reparto de las costas por profesionales, los escribanos absorverían entre el 40 y el 50\% de los costes. A bastante distancia de los jueces ordinarios, después de las asesorías y, finalmente, de los abogados. Quienes, en las causas civiles tendrían que ceñirse a unas minutas inferiores a la venteava parte del valor de la disputa. Otros profesionales o especialistas eran, en último lugar, los procuradores, respecto a los cuales podría o no constar el salario en autos que, en todo caso, seríaaun más bajo. En tanto que la presencia de peritos de valoración y demarcación de lindes rara vez supondría un gasto inferior a la décima parte del total ${ }^{46}$.

El coste total del seguimiento de un litigio variaba en función del número de actuaciones necesarias, además de otros factores como las multas, las minutas de facultativos, etc ${ }^{47}$. En la Galicia de Antiguo Régimen, los juzgados se autofinanciaban

\footnotetext{
45 Ibid., pp. 52-53.

${ }^{46}$ Ibid., pp. 56-60.

${ }^{47}$ Ibid., p. 61.
} 
en su totalidad a través de las condenas en costas, excepto en aquellos lugares en donde el juez gozase de salario. También contribuían al mantenimiento de los mismos las penas pecuniarias -aplicadas a la cámara del señor en caso de incumpliento de la parte condenada-. Éstas solían ser tasadas por los jueces ortigueireses en unos 400 o 600 maravedís -1.000 como mucho-. Cantidades que, aunque ayudaban, distaban de ser garantía económica suficiente para el funcionamiento de los juzgados y, mucho menos, vía de incremento del haber patrimonial de la casa nobiliaria correspondiente.

\section{LA SOCIOLOGÍA DE LOS JUZGADOS}

\subsection{El perfil social del litigante}

Atendiendo a las causas vistas según muestreos, se concluye en rasgos generales una litigiosidad predominante entre vecinos de la misma jurisdicción o próximas, sin llegar al $10 \%$ el porcentaje de demandantes de fuera del área de Ortigueira y, solamente, un $0,23 \%$ de demandados. Entre los pocos litigantes foráneos encontrados se trataría, además, de vecinos de localidades relativamente cercanas -Riobarba, Viveiro, A Coruña-, emigrantes retornados de Castilla, comerciantes o marineros de paso. Es la gente del común en un $88 \%$ de las veces la que se dirige a estos tribunales, tanto bajo el rol de demandantes como de demandados. No obstante, la justicia ordinaria abre también la posibilidad de atender a las élites locales que, de hecho, acuden en un $12 \%$-casi siempre, como demandantes- y por las mismas causas que sus convecinos labradores -derechos sobre la tierra y el patrimonio familiar-. Según participación por estatus social de los litigantes:

\begin{tabular}{|l|c|c|c|c|c|c|}
\cline { 2 - 7 } \multicolumn{1}{c|}{} & \multicolumn{2}{c|}{ Demandantes } & \multicolumn{2}{c|}{ Demandados } & \multicolumn{2}{c|}{ Totales } \\
\cline { 2 - 7 } \multicolumn{1}{c|}{} & No & \% & No & $\%$ & No & $\%$ \\
\hline Eclesiásticos & 11 & 2,63 & 2 & 0,48 & 0 & 0 \\
\hline Hidalgos & 15 & 3,59 & 5 & 1,2 & & \\
\hline Regidores & 9 & 2,15 & 0 & 0 & & \\
\hline Profesiones liberales & 8 & 1,92 & & & 50 & 12 \\
\hline
\end{tabular}

Cuadro 7. Élites locales litigantes en los juzgados del área de Ortigueira en el siglo XVII FUENTE: AHUS, serie judicial civil, Ortigueira, Exp. 1-1.234.

Raras resultan las ocasiones de enfrentamiento entre dos partes privilegiadas en la misma causa. Obvia señalar la ausencia de la nobleza en unos tribunales nacidos 
de su poder jurisdiccional, con lo que las causas que pudieren ocasionarse entre ésta y el pueblo se interpondrían, directamente, ante la Real Audiencia. Por su parte, en la categoría llamada "profesiones liberales" se contienen los asuntos que abogados y escribanos dirigieron a las audiencias señoriales, fundamentalmente, buscando pasar escrituras a documentos públicos. Característica, a mayores, inmanente al perfil común de los litigantes es el analfabetismo que, junto a la no obligatoriedad de dotarse de abogado en las demandas, originó que se recurriese con harta frecuencia al fenómeno de la delegación de escritura en personas alfabetizadas de la comunidad ${ }^{48}$. Si acaso el analfabetismo resultó todavía mayor en el caso de las mujeres que figuran como actoras o demandadas en los litigios, entre las cuales solo las hidalgas podían garabatear su nombre. Hay que señalar que la exigencia legal de ser representadas por sus maridos o tutores -las menores de 25 años no emancipadas- reduce la presencia femenina en los encabezamientos de demandas respecto al conjunto de interesadas en las causas que otros presentaron por ellas. En su propio nombre, las mayores de edad solteras y viudas encabezan un 14,38\% del total de causas elevadas a los juzgados del área de Ortigueira, figurando como actoras en un $9,6 \%$ de los casos y como demandadas en un $4,07 \%$, con una menor coincidencia aun de mujeres enfrentadas en parte y contraparte $(0,96 \%)$.

\subsection{Los jueces}

El primer aspecto a tener en cuenta al analizar el peso social del régimen señorial es que, en todas las jurisdicciones, el señor gozaría de cierto control sobre los oficiales del concejo y, muy particularmente, sobre el merino, juez o alcalde, que solía ser nombrado directamente por él, cuando no a propuesta de los notables locales ${ }^{49}$. Esto abrió a menudo la posibilidad de servirse de oficiales para presionar a los vasallos. Lo que, unido a la proliferación de pequeños cotos y escribanos, fue considerado por autores de la época como una de las causas del pésimo estado de la justicia en el Reino de Galicia y de la multitud de pleitos suscitados a cada paso $^{50}$. En las jurisdicciones

\footnotetext{
${ }^{48}$ PETRUCCI, A. (1999). Alfabetismo, escritura, sociedad. Barcelona: Gedisa, p. 105.

${ }^{49}$ La designación de jueces en los señoríos gallegos de los siglos XVII y XVIII dependió de un cúmulo de circunstancias como la edad, la idoneidad física, la experiencia en el gobierno de la comunidad y las fidelidades a un señorío particular.Partiendo de éstas, se contemplaron básicamente cuatro modalidades de nombramiento: la designación directa, la elección entre varios candidatos, la elección popular confirmada a posteriori y la celebrada mediante asamblea abierta. GONZÁLEZ FERNÁNDEZ, X. M. (1999): Los caracteres socio-profesionales de los oficiales de la administración de justicia en Galicia (1640-1820). La burocracia judicial de Bouzas, Vigo y Santiago, Vigo: Instituto de Estudios Vigueses, p. 96.

${ }^{50}$ Pegerto Saavedra indica que en un folleto encontrado en la Biblioteca Nacional (Madrid) se dice: "el juez de diez o veinte vasallos (...) ya se sabe que quando más será el criado del dueño del coto, y quando no biba el dueño dentro del coto eligirá un vasallo labrador, y éste no ha de ser el que tiene con que sustentarse, sino el más pobre que no pueda faltar a la obediencia del dueño". SAAVEDRA FERNÁNDEZ, P. (1985). Economía, Política y Sociedad en
} 
de Ortigueira primaba la designación directa por el señor -a propuesta de las élites locales-. Nombramiento que solía recaer en la hidalguía de las villas -apellidos Pita Tordesillas y Prado, Méndez de la Torre, Sanjurjo Montenegro, Bouza de Galdo, etc.-, en tanto eran preferidos los labradores ricos para las jurisdicciones más ruralizadas -Castaño, Gómez, Fernández, Mayoral y López-. También se sospecha de segundones de la nobleza en el oficio de judicatura al contarse apellidos como Bahamonde y Andrade en la audiencia de As Pontes o Pardo de Lama y Andrade en Mogor y Bares.

En cualquier caso, lo dicho no deja de constituir aproximaciones -no descabelladas- sobre la procedencia de los jueces. De la capacidad de firmar con buena caligrafía se deduce el rango acomodado de los justicias de jurisdicciones intermedias -Cerdido, Mañón, As Ribeiras- en el seno de las elevadas tasas de analfabetismo predominantes en la sociedad gallega del siglo XVII. No en vano fue tan criticada la escasa -o nula- formación de los jueces de señorío. Con todo, respecto a lectoescritura dicha crítica falla en las jurisdicciones de Ortigueira, donde solo uno de los 38 jueces recontados no firma: Pedro de Vilarelle, "el Viexo", juez del coto de Cerdido en 1633/34. Y, dentro de los que firman, son 23 los que lo hacen con buena o muy buena caligrafía y 14 los que firman más rudimentariamente - entre los que se cuentan los López, Gómez, etc., de los cotos redondos-. En cuanto a formación académica, a medida que se acerca el último tercio del siglo, se nota una tendencia al cumplimiento de la Pragmática dada por Isabel I en 1493, sobre la obligación de los candidatos a judicatura en cursar diez años de leyes civiles y canónicas ${ }^{51}$. Una mejoría que se desprende de la presencia de algún juez letrado, como el Licenciado Don Sebastián Lorenzo de Tapia, en la jurisdicción de Ortigueira: "En la villa de santa marta, A beinte y un días del mes de maio de seisçientos ochenta y quatro Años ante su merced el Liçenciado Don Sebastian Lorenzo de Tapia Abogado de los Reales Consejos Alcalde y Justiçia mayor en dicha villa y su jurisdicion" ${ }^{2}$.

\subsection{Los contadores-partidores}

Acudir a las instancias de justicia que señores temporales y monarquía habían establecido en los distintos territorios con el fin de mantener el orden público, así como castigar a los contraventores de las leyes, no fue la única vía de resolución ${ }^{53}$. Se extrae

Galicia... op., cit., p. 463.

${ }^{51}$ ROLDÁN VERDEJO, R. (1989). Los jueces de la Monarquía Absoluta. Su estatuto y actividad judicial. Corona de Castilla. Siglos XVI-XVIII. Santa Cruz de Tenerife: Universidad de La Laguna, p. 79.

${ }^{52}$ Ejemplificado a través del caso de partija de bienes de Juan de la Peña de Villar y Ana López Faxardo, vecinos de San Cristovo de Couzadoiro, a petición de sus hijos. Fechada de 3 de septiembre de 1683 a 21 de marzo de 1684. AHUS, serie judicial civil, Ortigueira, Exp. 1.236.

${ }^{53}$ IGLESIAS ESTEPA, R. (2001). "La conflictividad 'sorda': un estudio sobre la criminalidad a finales del Antiguo 
de los resultados hallados del Cuadro 3 que los asuntos llegados a pleito suman una minoría en las causas tratadas, pues el recurso a acuerdos entre partes enfrentadas se volvió una práctica muy usual que contaba, además, con el respaldo de la legislación castellana. Sin embargo, esto es algo que se sale del alcance de las fuentes manejadas -de naturaleza judicial-. Eso sí, los jueces se encontraban debidamente acompañados de asesores letrados - en las audiencias mayores- y de "hombres buenos", peritos, contadores-partidores o "expertos" locales en las causas civiles. Lo difícil de precisar son las características de dichos hombres, a quienes se les presumía "sufiencia e indiferencia" 54 para resolver en litigios penales, y también civiles, llegando a rozar la parajudicialidad.

Dónde hubiesen adquirido conocimientos de lecto-escritura y cómputo sigue constituyendo una incógnita. Si bien puede apuntarse su procedencia social al sector rico de la labranza. En ocasiones, los mismos escribanos - como Juan Dareal o el juez Pedro Pita- podían ejercer también como partidores. Tampoco faltarían veces en las que los conocimientos del oficio se transmitiesen de padres a hijos. Véase la actuación de los contadores Pedro y Alonso Garrote en Cerdido y Cedeira en las partijas y tutelas del muestreo de 1639-49. Por lo general, los nombres de "hombres buenos" se repiten en los asuntos elevados a las audiencias. Es claro que el saber comunitario no excluía la cultura escrita para insertarse en el mundo jurídico letrado, intelectualmente tan alejado del campesinado. En este sentido, resultan pocos los ejemplos de contadores-partidores sin rudimentos de firma. Es más, el común de cuentas -tanto partijas como tutelasson tasadas y redactadas por los propios "hombres buenos" que, una vez finalizadas, extenderían los documentos a juez y escribano a fin de que las partes consintiesen. De hecho, la propia falta de papeles obligaba a que los contadores dirigiesen escritos de su puño y letra al juez, pidiéndole compeler a las partes a su entrega $a^{55}$. De modo que el juicio de los alcaldes ordinarios, jueces y merinos se vería salvaguardado por el auxilio de estos "peritos", aunque sin por ello perder importancia la actividad de las audiencias de señorío en el seno de un Ordenamiento cuyo primer peldaño se destinó a solventar la litigiosidad más cotidiana.

Régimen”. Obradoiro de HistoriaModerna, 10, p. 275.

${ }^{54}$ SHARPE, J. A. (1983). "Such Disagreement betwyx Neigbours: Litigation and Human relations in Early Modern Age”. BOSSY, J. (dir.): Disputes and settlements: law and human relations in the west. Cambrigde, p. 168. Sobre infra y parajudicialidad, consúltese el trabajo clásico de Benoît Garnot (1996). L'infrajudiciaire du Moyen Age à l'époque contemporaine, Dijon: Publications de 1'Université de Bourgogne.

${ }^{55}$ Rendición de cuentas de tutela de las hijas de Bartolomé de Vilar Novo, vecino de la feligresía de Esteiro (jurisdicción de Cedeira). AHUS, serie judicial civil, Ortigueira, Exp. 26. 


\section{CONCLUSIONES}

La jurisdicción señorial, "delegada", "ordinaria delegada", "especial" o "de privilegio" o, simplemente, "ordinaria inferior" ha resultado, a menudo, menospreciada por la historiografía gallega, considerándola subordinada a Real Audiencia y, hasta cierto punto, inservible debido a las veleidades de los señoríos y a las amplias competencias de la Audiencia. Sin embargo, el tema no fue estudiado con la suficiente profundidad como para suponer la ausencia de juez en señoríos y reducir su función a un acto meramente protocolario. Si no, más bien, se observa lo contrarioen las tierras de Ortigueira, donde cada una de sus jurisdicciones se hallaba proveída de audiencia en activo. Desde las cuales, por si la fuente de justicia "no fuera tan limpia", podrían los vasallos apelar en segunda a la Real Audiencia del Reino. Por todo ello, hay que estudiar los juzgados de señorío en sí mismos, como un engranaje inicial del Ordenamiento Jurídico, más allá de reducirlos a vestigios de la justicia medieval.

Mirando hacia la parte técnica, no parece corresponderse la opinión de los coetáneos con la práctica inexistencia de veleidades por los justicias ortigueireses. No obstante esto atienda a la escasa variedad de asuntos, que incluso exigían más del refrendo delos jueces que de su propia capacidad de juzgar. Cabe tener en cuenta, por otra parte, que los justicias señoriales se acompañaban de escribanos, asesores letrados -doctos en leyes- y expertos de la comunidad - "hombres buenos"- a la hora de emitir su auto. Como tampoco alimentaba su veleidad la naturaleza de las causas: de escasa entidad y, mayoritariamente, concernientes a asuntos familiares, privados. En un tercer nivel explicativo, la sobreabundancia de causas patrimoniales vendría condicionada por el predominio de la familia nuclear frente a la familia troncal propia del interior de Lugo, con un sistema hereditario basado en la mejora corta. A la par de un mercado matrimonial prolífero en segundas nupcias, que hacía concurrir hijos de matrimonios distintos a una misma herencia. Además de ello, si en la generalidad galaico-occidental los excedentes económicos de la implantación del maíz habían contribuído a desplazar la litigiosidad familiar al seno de la comunidad avanzando el siglo XVII ${ }^{56}$, el área ortigueiresa a penas experimentaríadicho cambio de tendencia debido a la tardanza en la implantación del maíz sobre los cereales tradicionales.

${ }^{56}$ I. DUBERT GARCÍA (1992). Historia de la familia en Galicia ... op., cit., pp. 328-329. 


\section{BIBLIOGRAFÍA}

ARTAZA MONTERO, M. y GONZÁLEZ RÍOS, M. L. (1993): Las juntas del Reino de Galicia en el siglo XVII. A Coruña: Fundación Pero Barrié de la Maza.

GARNOT, B. (1996). L'infrajudiciaire du Moyen Age à l'époque contemporaine, Dijon: Publications de 1'Université de Bourgogne.

DÁVILA DÍAZ, J. (1931). Geografía descriptiva de la comarca de Ortigueira. A Coruña: Deputación Provincial.

DUBERT GARCÍA, I. (1990). "La conflictividad familiar en el ámbito de los tribunales señoriales y reales en la Galicia del Antiguo Régimen (1600-1830)". Obradoiro de Historia Moderna: homenaje al Profesor Antonio Eiras Roel, pp. 73-102.

DUBERT GARCÍA, I. (1990): Historia de la familia en Galicia durante la época moderna. 1550-1830. (Estructura, modelos hereditarios y conflictividad). A Coruña: Ediciós do Castro.

EIRAS ROEL, A. (1984): "Sobre el origen de la Audiencia de Galicia y sobre su función de gobierno en la época de la Monarquía Absoluta”. Anuario de Historia del Derecho Español, LIV, Madrid, 1984, pp. 323-384.

EIRAS ROEL, A. (1989). "El señorío gallego en cifras: nómina y ranking de los señores jurisdiccionales". Cuadernos de Estudios Gallegos, 103, p. 131.

FERNÁNDEZ VEGA, L. (1982). La Real Audiencia de Galicia, órgano de gobierno en el Antiguo Régimen: 1480-1808, 3 Vol., A Coruña: Deputación.

GONZÁLEZ FERNÁNDEZ, X. M. (1995): La justicia local y territorial en la Galicia de Antiguo Régimen, Vol. I y II. Tesis inédita: Universidade de Santiago de Compostela.

GONZÁLEZ FERNÁNDEZ, X.M. (1997). La conflictividad judicial ordinaria en la Galicia Atlántica (1670-1820). Bouzas y otros juzgados gallegos del siglo XVIII, Vigo: Instituto de Estudios Vigueses (prólogo de P. Saavedra Fernández, p. 9).

GONZÁLEZ FERNÁNDEZ, X. M. (1999): Los caracteres socio-profesionales de los oficiales de la administración de justicia en Galicia (1640-1820). La burocracia judicial de Bouzas, Vigo y Santiago, Vigo: Instituto de Estudios Vigueses.

GRANADOS LOUREDA, E., (1976): Un ejemplo de comisariado político en la España del siglo XVIII: la Intendencia de Galicia. Tesis de licenciatura: Universidade de Santiago de Compostela.

HERBELlA DE PUGA, B. (1768). Derecho práctico i estilos de la Real Audiencia de Galicia. Santiago de Compostela: Imprenta de Ignacio Aguayo.

HESPANHA BOTELHO, A. M. (1994). As vésperas do Leviathan: Instituiçoes e poder político em Portugal. Séc. XVII. Lisboa: Almedina.

IGLESIAS ESTEPA, R. (2000). La conflictividad "sorda”: un estudio sobre la criminalidad a fines del Antiguo Régimen. Tesis de Licenciatura: Universidade de Santiago de Compostela. 
IGLESIAS ESTEPA, R. (2001). "La conflictividad 'sorda', un estudio sobre la criminalidad a finales del Antiguo Régimen. Obradoiro de Historia Moderna, 10, pp. 247-273.

IGLESIAS ESTEPA, R. (2004). Las Quiebras del orden cotidiano: comportamientos criminales en la sociedad gallega a fines del Antiguo Régimen. Tesis de Doctorado: Universidade de Santiago de Compostela.

IGLESIAS ESTEPA, R. (2007). Crimen, criminales y reos: la delincuencia y su represión en la antigua provincia de Santiago entre 1700 y 1834 . Vigo: Nigratea.

KAGAN, R. (1981). Lawsuits and litigants in Castile: 1500-1700, Chapel Hill: The University of North Carolina.

LÓPEZ DÍAZ, M. (1984): La justicia señorial en la Galicia del siglo XVIII. Tesis de Licenciatura: Universidade de Santiago de Compostela.

LÓPEZ DÍAZ, M. (1991): Oficios municipales de Santiago a mediados del siglo XVIII. A Coruña: Estudios Mindonienses.

LÓPEZ DÍAZ, M. (1992): "El Concejo de Lugo en los siglos XVI-XVII, su estructura orgánica y composición social”. En $1^{\circ}$ Simposio de Historia da Administración Pública. Santiago de Compostela: EGAP, pp. 363-377.

LÓPEZ DÍAZ, M. (1993/94): “Origen y configuración de una magistratura del señorío del arzobispo compostelano: el juez seglar de la Quintana (1545-1599)". Cuadernos de Estudios Gallegos, 41 (106), pp. 153-165.

LÓPEZ DÍAZ, M. (2006). "La administración de la justicia señorial en el Antiguo Régimen”. AHDE, LXXVI, pp. 559-583.

ORTEGO GIL, P. (2011). "La fuente limpia de justicia: la Real Audiencia de Galicia". En Czeguhn, I. (dir.). Die Höchstgerichtsbarkeit im Zeiltalter Karls V. Eine vergleichende Betrachtung. Baden Baden: Nomos.

PETRUCCI, A. (1999). Alfabetismo, escritura, sociedad. Barcelona: Gedisa.

PRESEDO GARAZO, A. (2004): "Un ejemplo de administración señorial secular en la Galicia del siglo XVI: el estado de Montaos". Anuario de Historia del Derecho Español, 74, pp. 701-757.

RÍO BARJA, X. (1990). Cartografía xurisdiccional de Galicia no século XVIII. Santiago de Compostela: Consello da Cultura Galega.

RIVERA ROUCO, E. (1976). Estudio sobre la historia de Puentes de García Rodríguez y su comarca. A Coruña: La Voz de Galicia.

ROLDÁN VERDEJO, R. (1989). Los jueces de la Monarquía Absoluta. Su estatuto y actividad judicial. Corona de Castilla. Siglos XVI-XVIII. Santa Cruz de Tenerife: Universidad de La Laguna.

SAAVEDRA FERNÁNDEZ, P. (1985): Economía, Política y Sociedad en Galicia: la provincia de Mondoñedo 1480-1830. Madrid: Xunta de Galicia.

SAAVEDRA FERNÁNDEZ. P. (1990). “Contribución al estudio del régimen señorial gallego". AHDE, LX, pp. 167-168. 
SANTOS IGLESIAS, A. S. (2008). La Casa de Amarante. Siglos XVI-XIX, Santiago de Compostela: Universidad [recurso electrónico]. 〈http://www.usc.es/hmoderna/web/ uploads/publicacions/arquivo/860/54099abf98-1 pst.pdf [Consultado: 02/12/2016].

SHARPE, J. A. (1983). "Such Disagreement betwyx Neigbours: Litigation and Human relations in Early Modern Age". BOSSY, J. (dir.): Disputes and settlements: law and human relations in the west. Cambrigde, pp. 167-187. 